Pak. j. sci. ind. res. Ser. A: phys. sci. 201356 (1) 6-13

\title{
Characteristics Assessment of Cooking Oil and Vanaspati Ghee
}

\author{
Aftab Ahmed Kandhro*, Razia Sultana, Rubina Saleem, Ambrat Lal and Arfa Yasmin \\ ACRC- PCSIR Laboratories Complex, Shahrah-e-Dr. Salimuzzaman Siddiqui, Karachi-75280, Pakistan
}

(received February 27, 2012; revised June 26, 2012; accepted July 4, 2012)

\begin{abstract}
Various physico-chemical characteristics of commercial cooking oil and vanaspati ghee of different brands collected from local market have been analyzed. All the characteristic parameters were analyzed using AOCS method, while fatty acids composition of samples were determined using gas chromatography (GC) coupled with flame ionization detector (FID). Physico-chemical characteristics of all cooking oils seem comparable with each other, however, vanaspati ghee samples showed different physico-chemical characteristics due to presence of high amount of trans fat. There is direct relation between physico-chemical characteristics such as moisture and impurities, iodine value, unsaponifiable matter, saponification value, refractive index, density and colour.
\end{abstract}

Keywords: physico-chemical parameters, fatty acid composition, GC-FID, cooking oil

\section{Introduction}

Vegetables oils are derived from plant sources like soybeans, palm, corn, melon, groundnut, sheabutter, cocnut, etc. Some of these vegetable oils are used for domestic (edible) and industrial purposes (oleo chemicals) (Hui, 1996).

Many oilseed crops are grown in Pakistan as a source of vegetable oil. These crops are grouped in two categories viz. conventional and non-conventional oilseed crops. Rapeseed-mustard, groundnut and sesame are conventional crops and are being grown in the country for a long period. Sunflower, soybean and safflower are non-conventional crops. There are also some oilseed crops, which are mainly used for industrial purposes, such as linseed and castor.

The quality of fats plays very important role in food processing technology. Oxidation of fat is the main reason of deterioration in the quality of foods and can directly affect many quality characteristics such as flavour, colour, texture, nutritive value, and safety of the food. The quality and dietary character of the edible oil have been a topic of concern among food scientists, nutritionists and consumers (Kandhro et al., 2008a).

Lipids provide a concentrated source of energy and essential fatty acids through dietary intake. They also serve as important constituents of cell walls and carrier of fat-soluble vitamins. In addition, lipids provide

*Author for correspondence; E-mail: chemist_afi@yahoo.com flavour, texture and mouth feel to the food (Shahidi et al., 1997). Vegetable oils, made up of lipids, are very common commodities in our daily life (Mikuma and Kaneko, 2010).

A variety of fats and oils are widely available for consumption in the form of cooking oil, health products and food ingredients, as well as for the manufacture of cosmetics, soap and surfactants (Kandhro et al., 2010b). Chemical composition of fats and oils and their specific properties have allowed them to be used as foods, fuels and lubricants. Fats and oils are naturally occurring substances that consist predominantly of mixtures of fatty acid esters of glycerol (Pitts and Thomson, 2003; Coulombe, 2002). Fatty acids (FA) in food and biological samples are commonly analysed by gas chromatography (GC) (James and Martin, 1952). Characterization and determination of various kinds of saturated, mono and polyunsaturated fatty acids together with their positional and geometrical isomers have been studied using GCFID and GC-MS methods (Kandhro et al., 2010a; 2010b; Kandhro 2008a; 2008b).

Naturally obtained animal fats and vegetable oils contain not only the content of triacylglycerols, also containing several groups of accompanying substances which may be useful as nutrients, but at the same time they are either objectionable from the point of view of sensory value such that they affect the taste, odour, colour, appearance and functional properties (Cmolík and Pokorny, 2000). 
Vanaspati are manufactured by hydrogenation of vegetable oils, during which a reduction in the unsaturation of oils and an increase in the isomerization at the double bonds take place. The trans isomers thus formed affect the physical and chemical properties of the final products as they have higher melting points and greater stability (Lo and Handel, 1983).

Edible fats and oils represent one of the primary constituents in the formulation and manufacture of products by the food industry. Extracted oils from wide range of different sources undergo supplemental transformations such as fractionation, hydrogenation, and interesterification prior to utilization for the diet. During processing, a variety of physico-chemical quality parameters of oil are monitored, including the determination of free fatty acids, moisture, peroxide value, iodine value, and saponification number to name just a few (O'Brien, 1998).

There is a strong evidence that rise in per capita income is related to an increase in cooking oil and vanaspati ghee consumption. These products are essential food items for human utilization. In this scenario there is a need to periodically monitor quality of cooking oils and vanaspati ghee sale at various stores and outlets in the country.

The article therefore, discusses the impact of processing and storage on quality of cooking oil and vanaspati ghee as reflected by change in important physical and chemical parameters.

\section{Materials and Methods}

Material. Eleven samples of cooking oils and eleven sample of vanaspati ghee were purchased from local super market of Karachi, Pakistan. The choice of the brands was based on the highest consumption among those available in the market. Cooking oil and vanaspati ghee samples were coded as (CO-1 to CO-11) and (VG1 to VG-11), respectively. Each sample was analysed in triplicate and the results were reported as mean \pm standard deviation.

Reagents. All reagents, chemicals and solvents used were purchased from E. Merck (Darmstadt, Germany). Standards of fatty acid methyl esters were purchased from Supelco (Bellefonte, PA, USA) and Sigma Aldrich Co. (St. Louis, MO, USA).

Determination of physico-chemical parameters. All physicochemical parameters such as free fatty acids
(FFA), peroxide value (PV), moisture and impurities $(\mathrm{M} \& \mathrm{I})$, iodine value, unsaponifiable matter, saponification value, refractive index at room temperature and at $40{ }^{\circ} \mathrm{C}$, density and measurement of colour content of the samples were analysed using official method AOCS (2004).

Preparation of fatty acid methyl esters. Fatty acid methyl esters (FAMEs) were prepared using IUPAC standard method 2.301 (IUPAC, 1979) for the determination of fatty acids composition of the cooking oils and vanaspati ghee samples by gas chromatography coupled with flame ionization detector (GC-FID). The peaks were identified by comparing the retention times with those of authentic standards (Supelco Sigma-Aldrich $\mathrm{Co}$ ), and reported as relative percentage of individual fatty acids (Fig. 1).

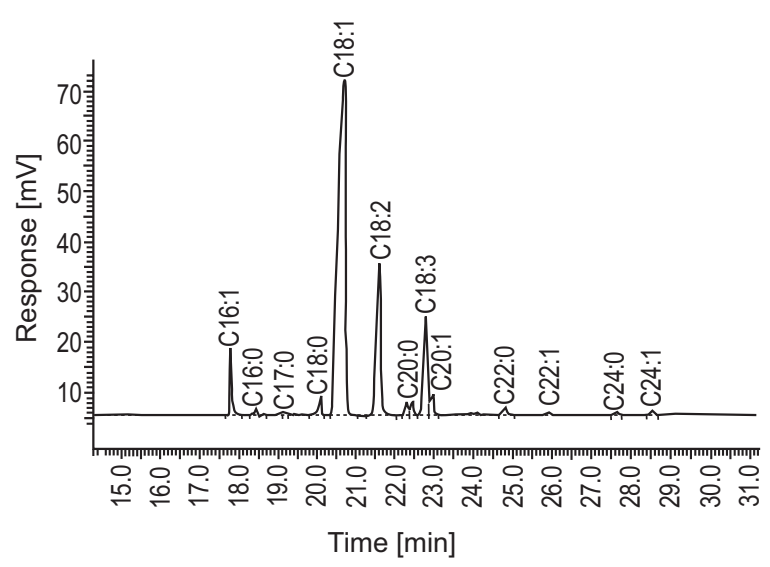

Fig. 1. Representative gas chromatogram of fatty acids of cooking oil.

GC-FID parameter/temperature programming. The analysis of FAMEs was performed on Perkin Elmer gas chromatograph model Clarus 500 instrument coupled with flame ionization detector. A polar capillary column Rtx- $2330(60 \mathrm{~m} \times 0.25 \mathrm{~mm} \times 0.20 \mu \mathrm{m}$, film thickness $)$ was used for the separation of fatty acid methyl esters. The initial oven temperature kept at $70^{\circ} \mathrm{C}$ for 5 min then ramped at $10^{\circ} \mathrm{C} / \mathrm{min}$ to $180^{\circ} \mathrm{C}$, followed by $3{ }^{\circ} \mathrm{C} / \mathrm{min}$ to final temperature $220^{\circ} \mathrm{C} \mathrm{kept}$ at this temperature for $8 \mathrm{~min}$. A sample volume of $0.3 \mu \mathrm{L}$ was injected (splitless). Nitrogen was used as carrier gas at a flow rate of $3 \mathrm{~mL} / \mathrm{min}$. The injector and detector temperature were 250 and $275^{\circ} \mathrm{C}$, respectively.

Statistical analysis. Two samples of each brands were collected and each sample was analyzed thrice and reported as mean $(n=2 \times 3)$ by using Microsoft Excel software. 


\section{Results and Discussion}

The study was conducted to evaluate the physical and chemical properties of some branded cooking oils and vanaspati ghee consumed for cooking. Results of all physico-chemical parameters (free fatty acids, peroxide value, moisture \& impurities, iodine value, unsaponifiable matter, saponification value, refractive index, density and colour) are summarized in Tables 1-2 for oil and ghee samples, respectively.

Free fatty acids (FFA). The free fatty acids (FFA) content is the important parameter for checking the quality of edible fats and oils; its range varies from 0.050 to $0.158 \%$ with the mean value of $0.10 \%$, whereas among the vanaspati sample, its values varies from 0.54 to $0.232 \%$, and mean value at $0.143 \%$. The average value of FFA is expressed as $\%$ of oleic acid. The high level of FFA indicates a higher percentage of fats/oils hydrolysis. Freshly processed edible fats and oils usually contain less than $0.1 \%$ FFA, however, degradation may occur in the oil during the storage, leading to liberation of FFA as reported by Wooley and Petersen (1981). The increase in FFA level is an indication to the beginning of spoilage of the oil (Elwarraky, 1977). The suggested FFA limit for cooking oils and vanaspati ghee by the Pakistan Standard is less than or equal to $0.2 \%$ (as oleic acid) (PS, 2003). All analyzed cooking oils and vanaspati ghee samples are found to have FFA values in the limits of Pakistan Standard.

Peroxide values. Peroxide values (PV) values for CO$11\left(0.280\right.$ meq $\left.\mathrm{H}_{2} \mathrm{O}_{2} / \mathrm{kg}\right)$ was lowest among all the cooking oil samples, while highest in C-10 (5.130 meq $\left.\mathrm{H}_{2} \mathrm{O}_{2} / \mathrm{kg}\right)$, the mean value at 1.954 meq $\mathrm{H}_{2} \mathrm{O}_{2} / \mathrm{kg}$. Vanaspati ghee samples contains lowest range $\left(0.34-2.11\right.$ meq $\mathrm{H}_{2} \mathrm{O}_{2}$ $/ \mathrm{kg}$ ) as compared to cooking oil samples, because vanaspati samples are hydrogenated and having low tendency to enhance the peroxide value. Pakistan Standard (PS, 2003) recommended that the PV values should not exceed 10.0 and 5.0 meq $\mathrm{H}_{2} \mathrm{O}_{2} / \mathrm{kg}$ for cooking oils and vanaspati ghee, respectively, to be valid for local and international trading. The differences in peroxide values may be resulted from the combined effects of factors such as prolonged contact of hot oil with atmospheric oxygen, presence of high level of moisture and considerable amounts of prooxidants (Nawar, 1996).

Moisture and impurities. The highest amount of moisture and impurities (M\&I) was found in CO-2 $(0.150 \%)$, whereas all others were less than $0.1 \%$ with the mean value of $0.070 \%$. Among vanaspati ghee highest amount was found in VG-1 (0.095\%), lowest in VG-4 (0.024\%) with the mean value of $0.058 \%$. However, these values fell within the range except only one sample CO-2 which also maintains the standard limit. The suggested standard limits of moisture and impurities for the cooking oil and vanaspati ghee were $0.150 \%$ (PS, 2003). Moisture content has an impact on oil stability; higher M\&I leads to higher rate of hydrolysis that enhanced the oxidation of oils (Balls et al., 1937). Water treatment during processing of oils and fats may be responsible for the higher level of moisture observed in cooking oils and vanaspati ghee samples.

Iodine value. The iodin value (IV) of cooking oil was found in the range from 99.0 to 127.3 (mean value: 108.6), while vanaspati ghee was in the range of 49.11-56.23 (mean value, 51.89). Oxidation or polymerization reactions tend to lower the iodine value of vegetable oil (Eckey, 1954). These values indicate a high degree of unsaturation and therefore, a high susceptibility to oxidative rancidity. The suggested limit of IV for cooking oils should be above than 80 (PS, 2003).

Unsaponifiable matter. Unsaponifiable matter includes those substances frequently dissolved in fats and oils, which cannot be saponified by the caustic alkalies but are soluble in the ordinary fat solvents. These include higher aliphatic alcohols, sterols, pigments and hydrocarbons. Mostly refined bleached and deodorized (RBD) fats and oils contain very low amount of unsaponifiable matter, however, marine oils contain excessive amount of these substances. Values of unsaponifiable matter of $\mathrm{CO}$ samples were ranged from 0.468 to $0.914 \%$ with mean value at 0.690 , similarly VG samples ranged from 0.351 to $0.982 \%$ with mean value at $0.691 \%$. The unsaponifiable matter $\%$ age by weight should not be maximum than 1.50 $\%$ (PS, 2003) for both cooking oils and vanaspati ghee; therefore all analyzed samples are found within the suggested limit.

Saponification value. The saponification values (SV) of analyzed cooking oil samples ranged from 185.2 to 194.5 , with mean value of $188.9 \mathrm{mg}$ of $\mathrm{KOH} / \mathrm{g}$, while in vanaspati ghee samples ranged from 192.3 to 198.4 , with mean value of $196.1 \mathrm{mg}$ of $\mathrm{KOH} / \mathrm{g}$. This result indicates that all the cooking oils have nearly similar saponification value. This finding agreed with the remarks of Mehran (1974), who reported that, prolonged storage of vegetable oils does not show significant change in saponification values. However, these values fall within the range 
Table.1. Characteristic physico-chemical parameters of branded vegetable cooking oil consumed in Pakistan

\begin{tabular}{llllllllllll}
\hline \hline Parameters & CO-1 & CO-2 & CO-3 & CO-4 & CO-5 & CO-6 & CO-7 & CO-8 & CO-9 & CO-10 & CO-11 \\
\hline FFA (\% as OA) & 0.088 & 0.095 & 0.071 & 0.105 & 0.124 & 0.157 & 0.112 & 0.158 & 0.057 & 0.050 & 0.077 \\
& \pm 0.004 & \pm 0.002 & \pm 0.003 & \pm 0.005 & \pm 0.00 & \pm 0.005 & \pm 0.004 & \pm 0.004 & \pm 0.002 & \pm 0.002 & \pm 0.001 \\
PV (meq / kg) & 1.380 & 3.758 & 1.798 & 2.280 & 2.130 & 1.717 & 1.614 & 1.110 & 0.292 & 5.130 & 0.280 \\
& \pm 0.05 & \pm 0.08 & \pm 0.04 & \pm 0.05 & \pm 0.09 & \pm 0.04 & \pm 0.05 & \pm 0.04 & \pm 0.01 & \pm 0.15 & \pm 0.01 \\
M \& I (\%) & 0.070 & 0.150 & 0.081 & 0.070 & 0.085 & 0.051 & 0.057 & 0.059 & 0.068 & 0.071 & 0.011 \\
& \pm 0.001 & \pm 0.005 & \pm 0.002 & \pm 0.003 & \pm 0.002 & \pm 0.002 & \pm 0.002 & \pm 0.001 & \pm 0.001 & \pm 0.003 & \pm 0.001 \\
IV & 101.2 & 104.3 & 106.8 & 108.5 & 106.7 & 111.3 & 109.3 & 108.3 & 111.7 & 127.3 & 99.0 \\
& \pm 1.52 & \pm 2.53 & \pm 3.24 & \pm 4.23 & \pm 5.21 & \pm 3.81 & \pm 2.93 & \pm 2.43 & \pm 3.56 & \pm 2.45 & \pm 2.13 \\
Unsaponifiable matter $(\%)$ & 0.671 & 0.914 & 0.468 & 0.754 & 0.604 & 0.721 & 0.810 & 0.648 & 0.751 & 0.680 & 0.563 \\
& \pm 0.03 & \pm 0.02 & \pm 0.01 & \pm 0.02 & \pm 0.03 & \pm 0.03 & \pm 0.04 & \pm 0.03 & \pm 0.02 & \pm 0.01 & \pm 0.01 \\
SV & 190.8 & 189.7 & 189.9 & 187.9 & 187.4 & 190.3 & 185.2 & 185.7 & 185.4 & 194.5 & 190.7 \\
& \pm 2.51 & \pm 3.23 & \pm 4.23 & \pm 2.35 & \pm 5.32 & \pm 5.87 & \pm 4.12 & \pm 2.52 & \pm 3.25 & \pm 4.56 & \pm 6.21 \\
RI at 40 C C & 1.467 & 1.466 & 1.465 & 1.466 & 1.465 & 1.466 & 1.466 & 1.466 & 1.465 & 1.468 & 1.465 \\
Density at room & \pm 0.05 & \pm 0.04 & \pm 0.06 & \pm 0.03 & \pm 0.02 & \pm 0.05 & \pm 0.06 & \pm 0.04 & \pm 0.05 & \pm 0.05 & \pm 0.02 \\
temperature & 0.915 & 0.912 & 0.915 & 0.916 & 0.914 & 0.915 & 0.914 & 0.916 & 0.915 & 0.915 & 0.910 \\
& \pm 0.03 & \pm 0.02 & \pm 0.04 & \pm 0.01 & \pm 0.04 & \pm 0.03 & \pm 0.03 & \pm 0.04 & \pm 0.04 & \pm 0.02 & \pm 0.02 \\
Density at 40 ${ }^{\circ} \mathrm{C}$ & 0.911 & 0.910 & 0.910 & 0.911 & 0.911 & 0.910 & 0.910 & 0.911 & 0.910 & 0.912 & 0.904 \\
& \pm 0.01 & \pm 0.04 & \pm 0.03 & \pm 0.02 & \pm 0.04 & \pm 0.01 & \pm 0.02 & \pm 0.02 & \pm 0.03 & \pm 0.02 & \pm 0.04 \\
Colour Red unit & 0.10 & 0.10 & 0.10 & 0.05 & 0.05 & 0.05 & 0.05 & 0.05 & 0.05 & 0.05 & 0.30 \\
$(1 "$ Cell) & \pm 0.002 & \pm 0.003 & \pm 0.003 & \pm 0.002 & \pm 0.001 & \pm 0.001 & \pm 0.002 & \pm 0.002 & \pm 0.002 & \pm 0.003 & \pm 0.005 \\
& 1.0 & 1.0 & 1.0 & 1.0 & 2.0 & 1.0 & 2.0 & 1.5 & 0.5 & 1.0 & 4.0 \\
\hline \hline & \pm 0.03 & \pm 0.04 & \pm 0.02 & \pm 0.02 & \pm 0.05 & \pm 0.04 & \pm 0.03 & \pm 0.05 & \pm 0.02 & \pm 0.03 & \pm 0.10 \\
\hline
\end{tabular}

Table. 2. Characteristic physico-chemical parameters of branded vanaspati ghee consumed in Pakistan

\begin{tabular}{|c|c|c|c|c|c|c|c|c|c|c|c|}
\hline Parameters & VG-1 & VG-2 & VG-3 & VG-4 & VG-5 & VG-6 & VG-7 & VG-8 & VG-9 & VG-10 & VG-11 \\
\hline \multirow[t]{2}{*}{$\mathrm{FFA}(\%$ as $\mathrm{OA})$} & 0.194 & 0.054 & 0.195 & 0.104 & 0.134 & 0.121 & 0.171 & 0.232 & 0.143 & 0.12 & 0.11 \\
\hline & \pm 0.003 & \pm 0.002 & \pm 0.005 & \pm 0.004 & \pm 0.003 & \pm 0.002 & \pm 0.003 & \pm 0.005 & \pm 0.002 & \pm 0.005 & \pm 0.002 \\
\hline \multirow[t]{2}{*}{ PV (Meq / kg) } & 0.94 & 0.76 & 1.68 & 0.34 & 0.86 & 2.11 & .81 & 1.42 & 1.24 & 1.22 & 1.52 \\
\hline & \pm 0.03 & \pm 0.02 & \pm 0.05 & \pm 0.01 & \pm 0.02 & \pm 0.07 & $1 \pm 0.05$ & \pm 0.03 & \pm 0.02 & \pm 0.02 & \pm 0.04 \\
\hline \multirow[t]{2}{*}{ M \& I (\%) } & 0.080 & 0.032 & 0.027 & 0.024 & 0.051 & 0.095 & 0.088 & 0.071 & 0.059 & 0.055 & 0.061 \\
\hline & \pm 0.003 & \pm 0.001 & \pm 0.001 & \pm 0.001 & \pm 0.005 & \pm 0.008 & \pm 0.003 & \pm 0.005 & \pm 0.03 & \pm 0.02 & \pm 0.02 \\
\hline \multirow[t]{2}{*}{ IV } & 56.23 & 51.70 & 51.60 & 54.55 & 50.98 & 55.19 & 49.11 & 50.23 & 50.39 & 50.44 & 50.33 \\
\hline & \pm 1.53 & \pm 1.85 & \pm 1.67 & \pm 1.25 & \pm 1.15 & \pm 1.45 & \pm 1.12 & \pm 1.21 & \pm 1.25 & \pm 1.11 & \pm 1.15 \\
\hline \multirow[t]{2}{*}{ Unsaponifiable matter (\%) } & 0.734 & 0.640 & 0.351 & 0.591 & 0.521 & 0.982 & 0.882 & 0.752 & 0.771 & 0.627 & 0.749 \\
\hline & \pm 0.03 & \pm 0.02 & \pm 0.01 & \pm 0.02 & \pm 0.02 & \pm 0.04 & \pm 0.03 & \pm 0.03 & \pm 0.03 & \pm 0.02 & \pm 0.03 \\
\hline \multirow[t]{2}{*}{ SV } & 194.9 & 197.2 & 196.0 & 192.3 & 193.5 & 194.8 & 198.1 & 197.4 & 196.3 & 198.1 & 198.4 \\
\hline & \pm 2.73 & \pm 3.42 & \pm 3.14 & \pm 4.17 & \pm 2.12 & \pm 2.11 & \pm 3.05 & \pm 3.22 & \pm 3.12 & \pm 3.52 & \pm 3.51 \\
\hline \multirow[t]{2}{*}{ Butyro reading at $40{ }^{\circ} \mathrm{C}$} & 51.0 & 51.7 & 51.6 & 51.7 & 51.1 & 52.1 & 52.3 & 51.8 & 51.6 & 51.5 & 51.8 \\
\hline & \pm 1.53 & \pm 1.42 & \pm 1.22 & \pm 1.31 & \pm 1.52 & \pm 1.43 & \pm 1.52 & \pm 1.44 & \pm 1.22 & \pm 1.15 & \pm 1.45 \\
\hline \multirow[t]{2}{*}{ Density at RT } & 0.909 & 0.910 & 0.915 & 0.918 & 0.916 & 0.912 & 0.918 & 0.926 & 0.918 & 0.915 & 0.916 \\
\hline & \pm 0.03 & \pm 0.04 & \pm 0.04 & \pm 0.03 & \pm 0.04 & \pm 0.03 & \pm 0.03 & \pm 0.05 & \pm 0.03 & \pm 0.04 & \pm 0.04 \\
\hline \multirow[t]{2}{*}{ Density at $40{ }^{\circ} \mathrm{C}$} & 0.905 & 0.905 & 0.910 & 0.915 & 0.905 & 0.904 & 0.903 & 0.903 & 0.902 & 0.905 & 0.905 \\
\hline & \pm 0.02 & \pm 0.04 & \pm 0.02 & \pm 0.02 & \pm 0.02 & \pm 0.03 & \pm 0.02 & \pm 0.02 & \pm 0.02 & \pm 0.02 & \pm 0.02 \\
\hline \multirow[t]{3}{*}{ M. $\mathrm{P}^{\circ} \mathrm{C}$} & 36.10 & 36.50 & 34.60 & 36.30 & 36.15 & 36.59 & 35.68 & 36.35 & 36.55 & 34.60 & 35.30 \\
\hline & \pm 1.24 & \pm 1.11 & \pm 1.05 & \pm 1.31 & \pm 1.22 & \pm 1.15 & \pm 1.16 & \pm 1.32 & \pm 1.12 & \pm 1.04 & \pm 1.32 \\
\hline & 0.40 & 0.51 & 0.31 & 0.20 & 0.41 & 0.05 & 0.30 & 0.22 & 0.15 & 0.33 & 0.20 \\
\hline Colour Red Unit & \pm 0.015 & \pm 0.02 & \pm 0.012 & \pm 0.005 & \pm 0.015 & \pm 0.002 & \pm 0.012 & \pm 0.005 & \pm 0.002 & \pm 0.012 & \pm 0.005 \\
\hline (1" Cell) & 3.0 & 3.0 & 3.0 & 3.0 & 3.0 & 3.0 & 3.0 & 3.0 & 3.0 & 3.0 & 3.0 \\
\hline Yellow Unit & \pm 0.11 & \pm 0.13 & \pm 0.12 & \pm 0.14 & \pm 0.11 & \pm 0.13 & \pm 0.12 & \pm 0.14 & \pm 0.13 & \pm 0.12 & \pm 0.14 \\
\hline
\end{tabular}


of $185-198 \mathrm{mg}$ of $\mathrm{KOH} / \mathrm{g}$ which was according to Pakistan Standard (PS, 2003).

Refractive index. The value for the refractive index of cooking oil at $40{ }^{\circ} \mathrm{C}$ were in the range from 1.465 to 1.468 (mean value at 1.466); the observed values of cooking oil was slightly comparable with each other, however, these values are lower than the reported values such as corn (1.4726), soybean (1.4728) and sunflower oil (1.4740) (Hui, 1996). The butyro reading at $40{ }^{\circ} \mathrm{C}$ for vanaspati ghee samples are in the range from 51.0 to 52.3 with the mean value at 51.7 .

Relative density. The high relative densities could be an indication of high molecular weight and unsaturation as the density of an oil increases with increase in molecular weight and unsaturation (Onyeka et al., 2005; Ohlson, 1983). The relative densities of cooking oil and vanaspati ghee at room temperature (RT) are in the range from 0.910 to $0.916 \mathrm{~g} / \mathrm{cm}^{3}$ (with the mean value of $0.914 \mathrm{~g} / \mathrm{cm}^{3}$ ) and similarly, 0.909 to $0.926 \mathrm{~g} / \mathrm{cm}^{3}$ (with the mean value of $\left.0.916 \mathrm{~g} / \mathrm{cm}^{3}\right)$, respectively, whereas at $40{ }^{\circ} \mathrm{C}$ the mean value of relative density for cooking oils and vanaspati ghee were determined to be 0.910 and $0.906 \mathrm{~g} / \mathrm{cm}^{3}$, respectively. The relative densities of cooking oil and vanaspati ghee are comparable with the reported vegetable oils corn oil, $0.916 \mathrm{~g} / \mathrm{cm}^{3}$; cottonseed oil, $0.914 \mathrm{~g} / \mathrm{cm}^{3}$; olive oil, $0.909 \mathrm{~g} / \mathrm{cm}^{3}$; rapeseed oil, 0.903-0.907 g/ $/ \mathrm{cm}^{3}$; sunflower oil, $0.9178 \mathrm{~g} / \mathrm{cm}^{3}$ and soybean oil, 0.9148 g/cm³; (Hui, 1996;Noureddini et al., 1992).

Melting point. Melting point of vanaspati ghee are in the range from 34.60 to $36.55^{\circ} \mathrm{C}$, and the mean value is 35.90 ${ }^{\circ} \mathrm{C}$. M.P of all the vanaspati ghee samples fell within the range of Pakistan standard which is $36 \pm 2{ }^{\circ} \mathrm{C}$ (PS, 2003).

Colour. Intense colour of vegetable oils depend mainly on the presence of various colouring pigments of plants such as caroteniods, chlorophyll, etc. which are effectively removed during refining and bleaching step of oil processing. Vegetable oils with minimum values of colour index are good for dieting purpose. The colour index of first three cooking oil (CO-1, CO-2 and CO-3) samples were at $(0.10 \mathrm{R}+1.00 \mathrm{Y})$, while other samples have same red colour index $(0.05 \mathrm{R}+1.00 \mathrm{Y})$, but small variation in their yellow colour index. Among the vanaspati ghee samples the colour index show small variation in red unit, but same for yellow unit, the mean value of vanaspati colour index is at $(0.28 \mathrm{R}+3.0 \mathrm{Y})$. It may be observed that all the samples are identical in their colour index property.

Fatty acid composition. Tables 3-4 show the average saturated and unsaturated fatty acid (FA) composition expressed in percentage of total fatty acids in cooking oils and vanaspati ghee samples. The samples of cooking oil and vanaspati ghee were coded as $\mathrm{CO}-1$ to $\mathrm{CO}-11$ and VG-1 to VG-11, respectively.

Saturated fatty acids with a chain length of C12:0-C16:0 are atherogenic, whereas stearic acid was reported as neutral health effect and oleic and polyunsaturated fatty acids have a lipid lowering effects (Aro, et al., 1997). Among the saturated fatty acid highest amount of palmitic acid (C16:0) and stearic acid (C18:0) were found, these fatty acids were in the range from 4.09 to $16.62 \%$ and 1.43 to $3.61 \%$, respectively in cooking oil samples, while other saturated fatty acids also present in considerable amount including, myristic (C14:0), (0.09 to $0.40 \%)$; arachidic (C20:0), (0.26 to $1.25 \%$ ); docosanoic acids (C22:0), (0.08 to $0.62 \%)$ and lignoceric acid (C24:0), (0.06 to $0.72 \%)$. Among saturated fatty acids (SFA), palmitic acid 16:0 was predominantly

Table 3. Fatty acids composition of branded vegetable cooking oil (g/100 g of FAME) consumed in Pakistan

\begin{tabular}{|c|c|c|c|c|c|c|c|c|c|c|c|}
\hline Fatty acids & $\mathrm{CO}-1$ & $\mathrm{CO}-2$ & $\mathrm{CO}-3$ & $\mathrm{CO}-4$ & $\mathrm{CO}-5$ & $\mathrm{CO}-6$ & $\mathrm{CO}-7$ & $\mathrm{CO}-8$ & CO-9 & $\mathrm{CO}-10$ & $\mathrm{CO}-11$ \\
\hline C14:0 & $0 \pm 0$ & $0 \pm 0$ & $0.09 \pm 0.002$ & $0.14 \pm 0.005$ & $0 \pm 0$ & $0 \pm 0$ & $0 \pm 0$ & $0 \pm 0$ & $0 \pm 0$ & $0.19 \pm 0.01$ & $0.40 \pm 0.01$ \\
\hline C16:0 & $4.24 \pm 0.12$ & $5.75 \pm 0.13$ & $6.04 \pm 0.12$ & $6.80 \pm 0.23$ & $5.82 \pm 0.15$ & $4.72 \pm 0.12$ & $4.84 \pm 0.15$ & $4.09 \pm 0.13$ & $4.85 \pm 0.15$ & $10.48 \pm 0.24$ & $16.62 \pm 0.21$ \\
\hline C16:1 & $0.28 \pm 0.01$ & $0.16 \pm 0.01$ & $0.17 \pm 0.01$ & $0.16 \pm 0.005$ & $0 \pm 0$ & $0.29 \pm 0.01$ & $0.29 \pm 0.01$ & $0.2 \pm 0.01$ & $0.29 \pm 0.01$ & $0.10 \pm 0.002$ & $0.23 \pm 0.01$ \\
\hline C18:0 & $1.74 \pm 0.1$ & $2.17 \pm 0.05$ & $2.57 \pm 0.08$ & $2.70 \pm 0.05$ & $1.43 \pm 0.05$ & $1.68 \pm 0.05$ & $2.23 \pm 0.03$ & $1.71 \pm 0.02$ & $1.73 \pm 0.05$ & $3.61 \pm 0.08$ & $2.19 \pm 0.05$ \\
\hline C18:1 trans & $1.34 \pm 0.05$ & $1.35 \pm 0.04$ & $1.22 \pm 0.04$ & $0 \pm 0$ & $0 \pm 0$ & $0.65 \pm 0.01$ & $0.94 \pm 0.01$ & $0.31 \pm 0.01$ & $0.56 \pm 0.02$ & $0.22 \pm 0.01$ & $0.28 \pm 0.01$ \\
\hline C18:1cis & $61.50 \pm 1.24$ & $50.82 \pm 1.25$ & $53.64 \pm 1.31$ & $49.78 \pm 1.25$ & $65.46 \pm 1.42$ & $63.96 \pm 1.32$ & $56.32 \pm 1.24$ & $63.47 \pm 1.52$ & $64.13 \pm 1.55$ & $20.63 \pm 0.57$ & $54.56 \pm 1.12$ \\
\hline C18:2 & $19.15 \pm 0.53$ & $28.91 \pm 0.85$ & $28.71 \pm 0.55$ & $31.53 \pm 0.75$ & $19.64 \pm 0.35$ & $18.59 \pm 0.45$ & $17.05 \pm 0.25$ & $19.46 \pm 0.35$ & $18.66 \pm 0.42$ & $55.47 \pm 1.34$ & $16.56 \pm 0.43$ \\
\hline C18:3 & $8.43 \pm 0.24$ & $8.68 \pm 0.32$ & $5.26 \pm 0.25$ & $6.02 \pm 0.15$ & $6.65 \pm 0.15$ & $7.35 \pm 0.15$ & $6.21 \pm 0.14$ & $8.45 \pm 0.15$ & $7.66 \pm 0.21$ & $8.70 \pm 0.24$ & $6.05 \pm 0.22$ \\
\hline C20:0 & $0.87 \pm 0.02$ & $0.52 \pm 0.01$ & $0.51 \pm 0.02$ & $1.16 \pm 0.03$ & $0.83 \pm 0.03$ & $1.25 \pm 0.02$ & $0.9 \pm 0.03$ & $1.09 \pm 0.05$ & $1.02 \pm 0.03$ & $0.26 \pm 0.01$ & $1.05 \pm 0.05$ \\
\hline C20:1 cis & $1.66 \pm 0.05$ & $0.95 \pm 0.04$ & $0.86 \pm 0.03$ & $0.52 \pm 0.02$ & $0.17 \pm 0.005$ & $1.17 \pm 0.01$ & $1.55 \pm 0.05$ & $0.93 \pm 0.03$ & $0.87 \pm 0.02$ & $0.00 \pm 0$ & $0.75 \pm 0.03$ \\
\hline $\mathrm{C} 22: 0$ & $.41 \pm 0.02$ & $.50 \pm 0.020$ & $47 \pm 0.03$ & $0.55 \pm 0.02$ & $0 \pm 0$ & $0.34 \pm 0.01$ & $0.62 \pm 0.01$ & $0.16 \pm 0.005$ & $0.23 \pm 0.01$ & $0.28 \pm 0.01$ & $0.08 \pm 0.001$ \\
\hline $\mathrm{C} 22: 1$ & $0 \pm 0$ & $0 \pm 0$ & $0.13 \pm 0.004$ & $0 \pm 0$ & $0 \pm 0$ & $0 \pm 0$ & $6.85 \pm 0.15$ & $0.13 \pm 0.005$ & $0 \pm 0$ & $0 \pm 0$ & $1.23 \pm 0.05$ \\
\hline $\mathrm{C} 24: 0$ & $0.16 \pm 0.01$ & $0.12 \pm 0.002$ & $0.13 \pm 0.002$ & $0.17 \pm 0.005$ & $0 \pm 0$ & $0 \pm 0$ & $0.72 \pm 0.03$ & $0 \pm 0$ & $0 \pm 0$ & $0.06 \pm 0.001$ & $0 \pm 0$ \\
\hline $\mathrm{C} 24: 1$ & $0.22 \pm 0.01$ & $0.07 \pm 0.002$ & $0.22 \pm 0.01$ & $0.47 \pm 0.02$ & $0 \pm 0$ & $0 \pm 0$ & $1.48 \pm 0.02$ & $0 \pm 0$ & $0 \pm 0$ & $0 \pm 0$ & $0 \pm 0$ \\
\hline
\end{tabular}


Table 4. Fatty acid composition of branded vanaspati ghee (g/100 g of FAME) consumed in Pakistan

\begin{tabular}{|c|c|c|c|c|c|c|c|c|c|c|c|}
\hline Parameters & VG-1 & VG-2 & VG-3 & VG-4 & VG-5 & VG-6 & VG-7 & VG-8 & VG-9 & VG-10 & VG-11 \\
\hline $\mathrm{C} 12: 0$ & $0 \pm 0$ & $0 \pm 0$ & $0.21 \pm 0.01$ & $0 \pm 0$ & $0 \pm 0$ & $0 \pm 0$ & $0 \pm 0$ & $0.29 \pm 0.01$ & $0.51 \pm 0.01$ & $0.51 \pm 0.01$ & $0 \pm 0$ \\
\hline C14:0 & $1.26 \pm 0.05$ & $0.97 \pm 0.02$ & $0.99 \pm 0.02$ & $1.09 \pm 0.05$ & $1.05 \pm 0.02$ & $1.71 \pm 0.05$ & $1.51 \pm 0.02$ & $1.37 \pm 0.02$ & $0.95 \pm 0.03$ & $1.32 \pm 0.03$ & $1.84 \pm 0.05$ \\
\hline C16:0 & $44.8 \pm 1.25$ & $44.82 \pm 1.05$ & $44.61 \pm 1.13$ & $43.79 \pm 1.21$ & $45.08 \pm 1.25$ & $46.53 \pm 1.55$ & $43.13 \pm 1.25$ & $45.45 \pm 1.25$ & $42.16 \pm 1.23$ & $44.47 \pm 1.23$ & $47.22 \pm 1.25$ \\
\hline C16:1 & $0 \pm 0$ & $0 \pm 0$ & $0.17 \pm 0.01$ & $0 \pm 0$ & $0 \pm 0$ & $0 \pm 0$ & $0 \pm 0$ & $0 \pm 0$ & $0 \pm 0$ & $0 \pm 0$ & $0 \pm 0$ \\
\hline C18:0 & $4.23 \pm 0.12$ & $5.49 \pm 0.15$ & $4.31 \pm 0.12$ & $5.64 \pm 0.25$ & $5.04 \pm 0.15$ & $3.82 \pm 0.12$ & $3.27 \pm 0.12$ & $4.35 \pm 0.15$ & $5.43 \pm 0.11$ & $4.33 \pm 0.15$ & $4.41 \pm 0.12$ \\
\hline C18:1 trans & $0.37 \pm 0.01$ & $2.85 \pm 0.08$ & $0.65 \pm 0.01$ & $1.28 \pm 0.05$ & $2.62 \pm 0.12$ & $9.22 \pm 0.25$ & $12.92 \pm 0.32$ & $8.04 \pm 0.25$ & $11.24 \pm 0.25$ & $16.25 \pm 0.35$ & $15.14 \pm 0.85$ \\
\hline $\mathrm{C} 18: 1 \mathrm{cis}$ & $38.91 \pm 1.14$ & $38.32 \pm 1.02$ & $38.19 \pm 1.21$ & $39.78 \pm 1.35$ & $38.58 \pm 1.22$ & $31.65 \pm 0.98$ & $26.79 \pm 0.73$ & $32.97 \pm 1.12$ & $33.81 \pm 0.75$ & $28.21 \pm 0.73$ & $27.98 \pm 0.25$ \\
\hline C18:2 & $9.88 \pm 0.18$ & $7.55 \pm 0.13$ & $10.26 \pm 0.15$ & $8.42 \pm 0.24$ & $7.32 \pm 0.25$ & $6.65 \pm 0.21$ & $12.38 \pm 0.22$ & $6.53 \pm 0.21$ & $5.22 \pm 0.12$ & $4.04 \pm 0.12$ & $3.41 \pm 0.11$ \\
\hline C18:3 & $0.28 \pm 0.01$ & $0 \pm 0$ & $0.25 \pm 0.01$ & $0 \pm 0$ & $0.31 \pm 0.01$ & $0.42 \pm 0.02$ & $0 \pm 0$ & $0.72 \pm 0.02$ & $0.37 \pm 0.01$ & $0.39 \pm 0.01$ & $0 \pm 0$ \\
\hline $\mathrm{C} 20: 0$ & $0.27 \pm 0.01$ & $0 \pm 0$ & $0.32 \pm 0.01$ & $0 \pm 0$ & $0 \pm 0$ & $0 \pm 0$ & $0 \pm 0$ & $0.28 \pm 0.01$ & $0.31 \pm 0.01$ & $0.48 \pm 0.01$ & $0 \pm 0$ \\
\hline $\mathrm{C} 20: 1 \mathrm{cis}$ & $0 \pm 0$ & $0 \pm 0$ & $0.25 \pm 0.01$ & $0 \pm 0$ & $0 \pm 0$ & $0 \pm 0$ & $0 \pm 0$ & $0 \pm 0$ & $0 \pm 0$ & $0 \pm 0$ & $0 \pm 0$ \\
\hline
\end{tabular}

present in vanaspati ghee samples ranging from 42.16 to $47.22 \%$, mean value $44.73 \%$, which clearly indicates that palm oil was frequently used in the production of vanaspati ghee. The second highest SFA was stearic acid, in the range from 3.27 to $5.64 \%$ in VG. On the other SFA, lauric, myristic, arachidic, docosanoic and lignoceric acids were also detected in VG samples but less than $2 \%$.

Unsaturated fatty acids (UFA) are categorized as an important group of fatty acids except for trans fatty acids. All the cooking oils contain higher amount of monounsaturated fatty acid (MUFA). Among the UFA, oleic acid (C18:1) was the principal benefactor in the range from 20.63 to $65.46 \%$ in cooking oil samples. Other members of MUFA are palmitoleic acid (C16:1), eicosenoic acid (C20:1 cis-11), docosenoic acid (C22:1), tetracosanoic acid (C24:0), and tetracosenoic acid (C24:1) in the range from 0.10 to $0.29 \%, 0.17$ to $1.66 \%, 0.13$ to $6.85 \%, 0.06$ to $0.72 \%$ and 0.07 to $1.48 \%$, respectively.

Among the VG samples highest amount of UFA were in VG-7 (52.09\%), and its range varied from 46.53 to $52.09 \%$, while palmitoleic $(0.17 \%)$ and eicosenoic acid $(0.25 \%)$ were found only in one sample (VG-3). Linoleic acid (C18:2) and linolenic acid (C18:3) are regarded as an essential class of polyunsaturated fatty acid (PUFA) and found in the range from 16.56 to $55.47 \%$ and 5.26 to $8.70 \%$, respectively in CO samples. Whereas in VG samples linoleic acid and linolenic acids were detected in the range from 3.41 to $12.38 \%$ and 0.25 to $0.72 \%$, respectively.

Figure 2 shows the total unsaturated, saturated fatty acids of CO and VG samples. All the cooking oils samples contain high amount of unsaturated fatty acids and $\mathrm{CO}$ samples show the small variation among the unsaturated and saturated ratios between each other, whereas unsaturated and saturated fatty acid composition in all VG samples show nearly equal amount.

Figure 3 represents the group and ratios between the total MUFA and PUFA of CO and VG samples. Total MUFA and PUFA were in the range from 20.73 to $66.49 \%$ and 22.61 to $64.17 \%$ in CO samples. Similarly VG samples were in the range from 39.09 to $45.05 \%$ and 3.41 to $12.38 \%$ respectively.

Figure 4 represents the group and ratios of SFA/UFA

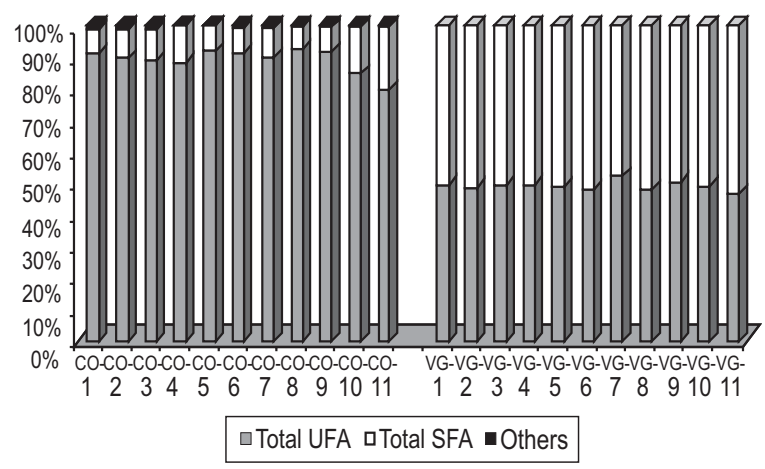

Fig. 2. Group of total unsaturated (UFA) total saturated (SFA) and other fatty acids of $\mathrm{CO}$ and VG samples.

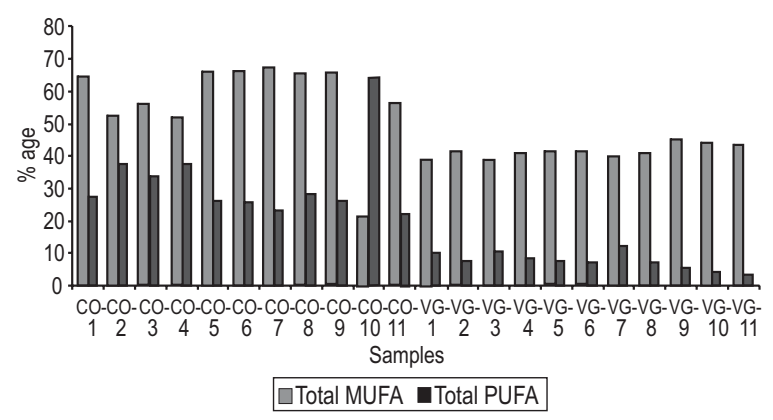

Fig. 3. Group and ratio of total mono unsaturated (MUFA) and total poly unsaturated fatty acids (PUFA) of CO and VG samples. 
of CO and VG samples. SFA/UFA ratio indicate the formation of SFA from the UFA; its range varies from 0.08 to 0.26 (CO-8, CO-11), while three samples (VG1, VG-3 and VG-4) of VG contain same ratio 1.02 except VG-2 (1.05). SFA/UFA ratio is important for the determination of quality of the fats and oils.

The majority of natural vegetable oils are rich in cisunsaturated fatty acids; the unsaturated constituents can be isomerized to the trans form during extraction or oxidative conversion by heating and by partial hydrogenation (Pérez-Serradilla et al., 2007). Structure, physical properties, chemical stability and the physiological (atherogenic) effects of trans fatty acids are different from cis unsaturated fatty acids, because they resemble with saturated fatty acids (Mensink and Katan, 1990). Trans fat (C18:1 trans) content in CO samples were in the range from 0.0 to $1.35 \%$, with mean value of $0.62 \%$ which is considerably lowest amount of trans fat in Pakistani CO samples, whereas some VG samples contains very high amount of trans fat such as VG-6 (9.22); VG-7 (12.92); VG-8 (8.04); VG-9 (11.24); VG10 (16.25); VG-11 (15.14\%), as shown in Fig. 5. The

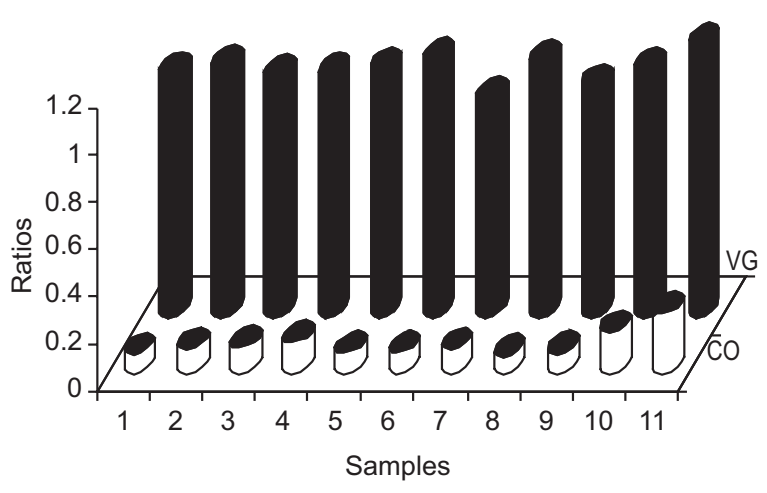

Fig. 4. Group and ratio of saturated/unsaturated fatty acids of $\mathrm{CO}$ and VG samples.

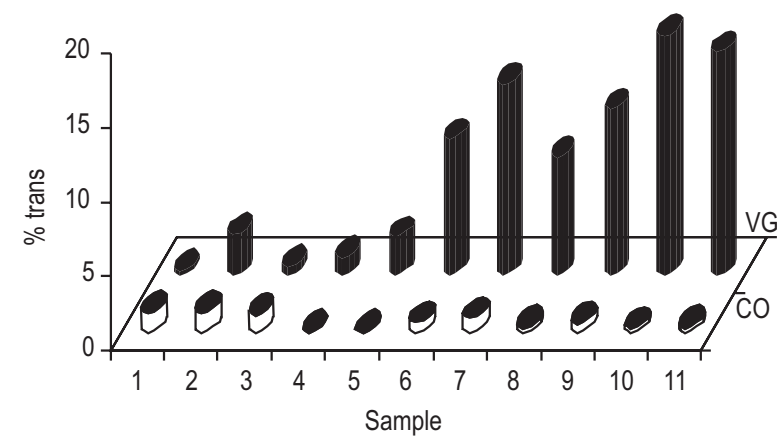

Fig. 5. Total trans fatty acids of CO and VG samples. range of trans fat in VG samples were from 0.37 to $16.25 \%$ with mean value of $7.33 \%$.

\section{Conclusion}

The present study indicates that all cooking oil and vanaspati ghee samples of different brands met the Pakistan Standards with reference to many physico-chemical parameters. However, some vanaspati ghee samples contain very high amount of trans fatty acid which is very harmful for the consumers' health. It is also concluded that, all selected branded samples have comparably same physicochemical characteristics; there is direct relation between fatty acid compositions. Other physico-chemical characteristics or consistency of the samples which indicates that same kind of blending have been used. Some important quality parameters such as free fatty acids, peroxide value, moisture and impurities also maintain the standard limit. It is also concluded that most of the cooking oils and some brands of vanaspati ghee sold/ marketed in Pakistan are of good quality.

\section{References}

AOCS, 2004. Official Methods and Recommended Practices of American Oil Chemists Society. V.C. Mehlenbacher et al. (eds), $5^{\text {th }}$ edition, American Oil Chemist Society, Champaign, Illinoise, USA.

Aro, A., Jauhiainen, M., Partanen, R., Salminen, I., Mutanen, M. 1997. Stearic acid, trans fatty acids, and dairy fat: effects on serum and lipoprotein lipids, apolipoproteins, lipoprotein(a), and lipid transfer proteins in healthy subjects. The American Journal of Clinical Nutrition, 65: 1419-1426.

Balls, A.K., Matlach, M.B., Trucher, I.W. 1937. The hydrolysis of glycerides by crude pancreas lipase. Journal of Biological Chemistry, 122: 125-137.

Cmolík, J., Pokorný, J. 2000. Physical refining of edible oils. European Journal of Lipid Science and Technology, 102: 472-486.

Coulombe, R. 2002. Chemical analysis of vegetable oils following spontaneous ignition. Journal Forensic Science, 47: 195-201.

Eckey, E.W. (ed.). 1954. Effect of polyethylene and polypropylene films on the stability of vegetable oils. In: Vegetable Fats and Oils, Reinhold Publishing Corp., New York, USA.

Elwarraky, 1977. Oil and Fats Technology. Ain Shams University Press, Cairo, Egypt.

Hui, Y.H. 1996. Bailey's Industrial Oil and Fat Products, Edible oil and Fat Products. Vol: 3, 600 pp., John 
Wiley and Sons, New York, USA.

IUPAC, 1979. Standards Methods for the Analysis of Oils, Fats and Derivatives. C. Paquot (ed.), pp. 96$98,6^{\text {th }}$ edition, International Union of Pure and Applied Chemistry, Pergamon Press, Oxford, UK.

James, A.T., Martin, A.J.P. 1952. Gas-liquid partition chromatography. The separation and micro-estimation of volatile fatty acids from formic acid to dodecanoic acid. Biochemical Journal, 50: 679-690.

Kandhro, A.A., Sherazi, S.T.H., Mahesar, S.A., Talpur, M.Y., Latif, Y. 2010a. Variation in fatty acids composition including trans fat in different brands of potato chips by GC-MS. Pakistan Journal of Analytical and Environment Chemistry, 11: 36-41.

Kandhro, A.A., Sherazi, S.T.H., Mahesar, S.A., Talpur, M.Y., Bhutto A.A., Abro K. 2010b. GC-MS Evaluation of fatty acid profile and lipid bioactive of partially hydrogenated cooking oil consumed in Pakistan. Pakistan Journal of Scientific and Industrial Research, 53: 316-322.

Kandhro, A., Sherazi, S.T.H., Mahesar, S.A., Bhanger, M.I., Talpur, M.Y., Arain, S. 2008a. Monitoring of fat content, free fatty acid and fatty acid profile including trans fat in Pakistani biscuits. Journal of the American Oil Chemists' Society, 85: 1057 1061.

Kandhro, A., Sherazi, S.T.H., Mahesar, S.A., Bhanger, M.I., Talpur, M.Y., Rauf, A. 2008b. GC-MS quantification of fatty acid profile including trans FA in the locally manufactured margarines of Pakistan. Food Chemistry, 109: 207-211.

Lo, Y.C., Handel, A.P. 1983. Physical and chemical properties of randomly interesterified blends of soybean oil and tallow for use as margarine oils. Journal of the American Oil Chemists' Society, 60: 815-818.

Mehran, M. 1974. Oil characteristics of Iranian walnuts. Journal of the American Oil Chemists' Society, 51: 477-478.

Mensink, R.P., Katan, M.B. 1990. Effect of dietary trans fatty acids on high-density and low-density lipoprotein cholesterol levels in healthy subjects. New England Journal of Medicine, 323: 439-445.

Mikuma, T., Kaneko, T. 2010. A quick discrimination of vegetable oil by solid-phase microextraction method. Forensic Science International, 198: 79-84.

Nawar, W.W. 1996. Lipids. Food Chemistry, R.F., Owen, (ed), pp. 225-320, $3^{\text {rd }}$ edition, Marcel Dekker, Inc. New York, USA.

Noureddini, H. Teoh, B., Davis, C.L. 1992. Densities of vegetable oils and fatty acids. Journal of the American Oil Chemists' Society, 69: 1184-1188.

O'Brien, R.D. 1998. Fats and Oils: Formulating and Processing for Applications, 694 pp., Technomic Publishing Company. Co., USA.

Ohlson, R. 1983. Structure and physical properties of fats. AOCS Monograph, 10: 44-55.

Onyeka, E.U., Onuegbu, N., Onuoha, N.U., Ochonogor, F. 2005. Effect of extraction pretreatment on the composition and characteristics of seed and pulp oil of African black pear (Dacryodes edulis). Nigerian Food Journal, 23: 13-20.

Pérez-Serradilla, J.A., Ortiz, M.C., Sarabia, L., Luque de Castro, M.D. 2007. Focused microwave-assisted Soxhlet extraction of acorn oil for determination of the fatty acid profile by GC-MS. Comparison with conventional and standard methods. Analytical and Bioanalytical Chemistry, 388: 451-462.

Pitts, S.J., Thomson, C.I. 2003. Analysis and classification of common vegetable oils. Journal Forensic Science, 48: 1293-1297.

PS, 2003. Pakistan standard specification for fats and oils (PS:221-2003 ${ }^{\circledR}$ ) (PSQCA, $3^{\mathrm{RD}}$ REV.), Pakistan Standards and Quality Control Authority, Standards Development Centre, Saddar, Karachi, Pakistan.

Shahidi, F., Wanasundara, P.K.J.P.D., Wanasundara, U.N. 1997. Changes in edible fats and oils during processing. Journal of Food Lipids, 4: 199-231.

Wooley, P. S., Petersen, 1981. Lipases. Their Structure, Biochemistry and Application. P. Wooley and S. Petersen (eds). Cambridge University Press. Cambridge, UK. 